
SAFETY IN RHEUMATOID ARTHRITIS

E. Chamizo ${ }^{1}$, E. González ${ }^{2}$, C. Carrasco ${ }^{1}$, S. Rojas ${ }^{1}$, J.J. Aznar ${ }^{1}$, P. Dorado ${ }^{2}$, A. Llerena ${ }^{2} .{ }^{1}$ Rheumatology, Hospital Mérida and CHU Badajoz, Mérida; ${ }^{2} \mathrm{CICAB}$, CHU de Badajoz, Badajoz, Spain

Background: Methotrexate (MTX) is the DMARD of choice in the treatment of rheumatoid arthritis (RA). Despite an acceptable efficacy, its use is limited by side effects. The most known adverse events (AE) are gastrointestinal, hepatic, and haematological.

Objectives: To study the effect of clinical characteristics and of different genetic single nucleotide polymorphisms (SNPs) related to the transport and metabolic pathways of MTX, on the toxicity of this compound, in a cohort of RA patients treated with MTX in monotherapy.

Methods: Observational study. Toxicity was defined as the occurrence of $A E$, global and of haematological, hepatic, and gastrointestinal nature. Factors under study: SNPs of transport (ABCB1 C3435T), glutamation (GGH T16C and FPGS G2782A), transmethylation (MTHFR C677T and MTHFR A1298C) and adenosine (AMPD1 C34T, ADA A534G, ITPA C94A). The association between SNPs and MTX toxicity was analysed using logistic regression models, assessing allele independence (Hardy-Weinberg equilibrium) and interaction with sex. Different models of inheritance of SNPs were analysed. The models were adjusted by the characteristics of the patient, of disease and of treatment. The haplotypes of the MTHFR SNPs (C677T and A1298C) were also analysed.

Results: Bivariate analysis showed that $\mathrm{AE}$, globally considered, are related to lower age at diagnosis $(\mathrm{OR}=0.98)$, female sex $(\mathrm{OR}=1.95)$, disease activity $(\mathrm{OR}=1.38)$, extra-articular manifestations $(\mathrm{OR}=1.84)$ and comorbidity $(\mathrm{OR}=1.14)$. For the SNPs, the $A / G$ genotype of the ADA A534G decreases the probability of $A E(O R=0.55)$; the $G / G$ of the ADA A534G increases the hepatic $A E(O R=10.1)$ and the genotypes $C / T$ and $T / T$ of the $A B C B 1$ C3435T decrease the risk of haematological $\mathrm{AE}$

According to the adjusted analysis, the probability of global $A E$ increased with the $\mathrm{C} / \mathrm{T}$ genotypes of MTHFR C677T (OR=1.85) and $\mathrm{C} / \mathrm{C}$ of $\mathrm{GGH}$ T16C $(\mathrm{OR}=2.53)$ and decreased with the $\mathrm{A} / \mathrm{G}$ of ADA A534G $(\mathrm{OR}=0.49)$. Gastrointestinal AEs were less frequent in patients with $A / G$ genotype of $A D A A 534 G(O R=0.49)$ and in men with $\mathrm{G} / \mathrm{A}$ of FPGS $2782 \mathrm{GAc}(\mathrm{OR}=0.29)$. The $\mathrm{G} / \mathrm{G}$ genotype of the SNP ADA_534AG was associated with a significant increase in hepatic $A E(O R=12.7)$, which was also observed in men with the MTHFR A1298C (OR=8.34). The T allele of the $A B C B 1$ C3435T decreases the probability of haematological $A E$, especially in women $(\mathrm{OR}=0.06)$. All the effects were independent of the characteristics of patient, disease and treatment. The $\mathrm{C} / \mathrm{C}$ haplotype of the combination MTHFR C677T and MTHFR A1298C increases the probability of global $(\mathrm{OR}=4.35)$ and hepatic $\mathrm{AE}(\mathrm{OR}=11.9)$ in men, but not in women.

Conclusions: SNPs related to the transport and metabolism of MTX are associated with liver toxicity of MTX.

Disclosure of Interest: None declared

DOI: 10.1136/annrheumdis-2018-eular.3088

\section{AB1297 HIGH PREVALENCE OF SERONEGATIVE RHEUMATOID ARTHRITISIN A MAYA-YUCATECO INDIGENOUS POPULATION: A COHORT COMMUNITY-BASED STUDY}

F. Morales-Arango ${ }^{1}$, J.F. Moctezuma ${ }^{2}$, A. Loyola-Sanchez ${ }^{3}$, H. Garcia $^{4}$, E. AlvarezHernandez ${ }^{2}$, C. García ${ }^{2}$, J. Alvarez-Nemegyei ${ }^{5}$, J. Vazquez-Mellado ${ }^{2}$, H. AyoraManzano $^{6}$, G. Cruz-Martin ${ }^{7}$, D. Flores-Aguilar ${ }^{6}$, R. Pereira-Zaldivar ${ }^{8}$, M. ZarateDominguez ${ }^{8}$, M. Mendoza ${ }^{8}$, I. Pelaez-Ballestas ${ }^{2}$, on behalf of GLADERPO. ${ }^{1}$ Faculty of Medicine, Universidad Autonoma del Estado de Puebla, Puebla; ${ }^{2}$ Rheumatology Unit, Hospital General de Mexico, Mexico, Mexico; ${ }^{3}$ University of Calgary, Calgary, Canada; ${ }^{4}$ Private Practice, Cancún; ${ }^{5}$ Hospital Star Medica; ${ }^{6}$ Universidad Autonoma de Yucatan, Merida; ${ }^{7}$ Faculty of Medicine, Universidad Nacional Autonoma de Mexico, Mexico; ${ }^{8}$ Hospital General de Valladolid, Valladolid, Mexico

Background: Eighty percent of people living with rheumatoid arthritis (RA) are seropositive. Recent studies show that seronegative RA is associated with a more aggressive clinical presentation; however, this association has not been studied in indigenous populations.

Objectives: To compare the clinical and radiographic characteristics, functioning and quality of life in a group of Maya-Yucateco indigenous patients with RA, based on their seropositivity Rheumatoid Factor (RF- IgM).

Methods: A community-based cohort was formed in 2014 with the aim of detecting and performing a community intervention in a Mayan Municipality in Mexico. Patients who fulfilled ACR/EULAR criteria $1987 / 2010$ for RA were included and rheumatologists evaluated them every 3 months. All evaluations were conducted in the community with the support of trained translators and included: 1 . Clinical examinations. 2. Laboratories (i.e. RF, ESR, CRP). 3. Radiographic evaluations. 4. Functioning (HAQ-DI) and quality of life (EQ5D-3L) assessments. 5.
Pharmacological treatment. 6. Non-pharmacological treatment: individual and group exercises.

A quantitative comparative analysis was conducted by dividing the cohort in seropositive and seronegative and comparing all variables measured using a $\chi^{2}$; test, Student's $t$-test or Mann-Whitney $U$ test, as well as Kruskall-Wallis test for the non-parametric variables.

Results: Twenty eight of 430 participants were diagnosed with RA (1.8\%, Cl95\%; 1.2 to 2.6 ), for an incidence $0.72 \%$ (Cl95\% 0.3 to 1.2 ) in 4 years. Seventy-eight\% were women, the mean age was 53.9 years (standard deviation $(S D)=13.2$ ) and the level of education was on average 2 years (0-5.5).

We observed high prevalence of family history of rheumatic disease $(75 \%)$, exposure to woodstove $(96.1 \%)$, and a Chikungunya virus infection (10.7\%) and RF$(65.3 \%)$.

The treatment given was methotrexate in $64.2 \%$ as monotherapy, and $21.4 \%$ in combination therapy. NSAIDs were prescribed in $98.2 \%$. Prednisone was prescribed at low doses ( $<7.5 \mathrm{mg} /$ day) in $14.2 \%$.

The level of pain/discomfort assessed through EQ-5D3L dimension was significantly higher in the seropositive group in comparison with the seronegative group. No other differences were detected between these groups (see Table).

Abstract AB1297 - Table 1

\begin{tabular}{lccc}
\hline Variable & $\begin{array}{c}\text { Seronegative } \\
(\mathrm{n}=17) \mathrm{n}(\%)\end{array}$ & $\begin{array}{c}\text { Seropositive } \\
(\mathrm{n}=9) \\
\mathrm{n}(\%)\end{array}$ & $\mathrm{p}$ value \\
\hline Family history of RD* & $16(94.1)$ & $5(55.5)$ & 0.01 \\
Work & $16(94.1)$ & $6(66.6)$ & 0.06 \\
DAS28, median (IQR) & $3.7(2.9-3.9)$ & $3.9(3.3-4.4)$ & - \\
Van der Heijde- modified Sharp score, mean (SD) & $93.4(13.0)$ & $110.2(7.8)$ & - \\
EQ5D-3L & & & 0.04 \\
Pain/discomfort & & & \\
No problems & $2(12.5)$ & $1(11.1)$ & \\
Some problems & $11(68.7)$ & $2(22.2)$ & \\
Extreme problems & $3(18.7)$ & $6(66.6)$ & \\
Disability (HAQ>0.8) & $3(17.6)$ & $4(44.4)$ & 0.1 \\
\hline
\end{tabular}

${ }^{*} \mathrm{p} \leq 0.04$

RD rheumatic diseases; DAS-28 disease activity score; HAQ Health Assement Questionnaire.

Conclusions: The prevalence with negative RF is high in the community studied however, no differences were observed in the variables studied, except in pain.

Acknowledgements: Funding: CONACYT-233777

Disclosure of Interest: None declared

DOI: 10.1136/annrheumdis-2018-eular.5944

\section{AB1298 PREVALENCE OF RHEUMATIC DISEASES IN COLOMBIA BY CITY}

J. Londono ${ }^{1}$, F.M. Cuervo ${ }^{1}$, J.C. Rueda ${ }^{1}$, E.L. Saldarriaga ${ }^{1}$, I. Angarita ${ }^{1}$, I. Peláez ${ }^{2}$, E. Forero ${ }^{3}$, J. Ramirez ${ }^{4}$, C. Toro ${ }^{4}$, A. Santos ${ }^{1} .{ }^{1}$ Grupo de investigación Espondiloartropatias, Universidad de La Sabana-Hospital Militar Central, Chía, Colombia: ${ }^{2}$ Hospital General de México, Ciudad de México, Mexico; ${ }^{3}$ Universidad del Norte, Barranquilla; ${ }^{4}$ Asociación Colombiana de Reumatología, Bogotá, Colombia

Background: Knowledge of the prevalence of rheumatic diseases allows us to design public health strategies for their comprehensive care and reduction of the costs derived from the potential complications of these diseases.

Objectives: To describe and compare the prevalence of rheumatic disease between six cities from Colombia.

Methods: The study was developed according the COPCORD epidemiological strategy designed for the identification, prevention and control of rheumatic diseases in developing countries.

A cross-sectional analytical study including individuals older than 18 years was designed with a calculated sample size of 6528 people (2336 from Bogotá, 1220 from Medellín and Cali each, 746 from Barranquilla, from Bucaramanga and Cúcuta each one). Prevalence of each rheumatic disease was compared between the evaluated cities from Colombia.

Results: A total of 6693 individuals from six cities of Colombia were evaluated. The average age was $46,40 \pm 18,35$ and $4283(64 \%)$ individuals were women. The cities with the highest frequency of positive COPCORD population were Bogotá $36,6 \%(n=1813)$, Cali 19,1\% $(n=945)$ and Medellín 15,9\% $(n=789)$. Abstract AB1298 - Figure 1

The majority of musculoskeletal pain manifested by the population correspond to non-specific muscular discomfort (MMNE). Osteoarthritis (OA) is the most prevalent rheumatic disease $(10,81 \%, 95 \% \mathrm{Cl}, 9,68-12,06 \%)$. Mechanical low back pain was the most frequent disease in Barranquilla, with a prevalence of $11,91 \%$ mainly in men $15,9 \%(95 \% \mathrm{Cl}, 11,24-21,92 \%)$. Regarding to rheumatoid arthritis (RA) it was more prevalent in women, between 40 and 59 years. It was found to 